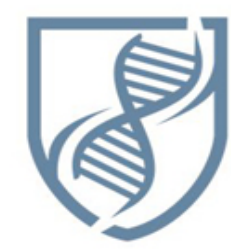

Journal of Bioscience and Applied Research

\section{JBAAR}

WWW.JBAAR.ORG

\title{
Intestinal Parasitic infections Among ELMekhwah residents, Saudi Arabia : Prevalence and relationship between parasite and host
}

\author{
Ali Al Ghamdi \\ Biology Department, College of Science, Al Baha University, \\ Al Baha, Saudi Arabia \\ (Email: al-zandi@hotmail.com)
}

\begin{abstract}
The present study was conducted randomly at El Mekhwah Province, Kingdom of Saudia Arabia to determine the prevalence of the intestinal protozoa and Helminth parasites during 2013-2014. Examination of 210 stool samples revealed that $16.19 \%$ of the visitors harbored intestinal protozoa, the most common parasites found were Entamoeba histolytica (6.19\%), Entamoeba coli (6.66) and Giardia lambia (3.33\%) While investigation of 300 stool samples for parasitic helminthes showed that 31 (10.33) were infected with Hymenolips nana, (4.33\%) for Ascaris lumbricoides $4 \%$ and $2 \%$ for Taenia saginata.
\end{abstract}

Keywords: ELMekhwah ,Helminth, Parasitic infections, Saudi Arabia

\section{Introduction}

Parasites are organisms that spend their life cycle or period of it depending on other organisms searching for food and shelter (Chandeler and Read, 1964). Intestinal parasites (Protozoa and helminthes) usually populate the gastro-intestinal tract in human and other animals as they prefer the intestinal wall and cavity. Intestinal infections are the most prevalent in tropical and subtropical regions of the undeveloped world where adequate water and sanitation facilities are lacking (Savioli et al., 2004). The prevalence and spread of these prasites have been found to be related to the educational, environmental, sanitary and socioeconomic conditions of the people (Albonico et al., 1993; Eve et al., 1998; Celiksoz et al., 2005; Taha et al., 2013). Many surveys have been carried out in various regions of KSA including Abha district and Al-Khobar (Abahussain, 2005), Mekkah (Wakud et al., 2009) and
Al-Baha (Mohammad and Koshak, 2011) concerning female house keepers, food handlers whom usually expatriate workers. The present study was designed to investigate the prevalence of the intestinal parasitosis (protozoa, Helminthes) infections among El-Mekhwah Province on patients visited the Governmental hospitals from Saudi and other nationalities during the years of 2013 and 2014.

\section{Materials and Methods}

El-Mekhwah province located in the south western part of Al-Baha region in Saudi Arabia and form the main part of Tihama strip. It is surrounded by mountains on all sides; east and north by sarwat, in the west by Shada and in the south by Nahabah mountains. Although this province is very large in the area, the population does not exceed 21000 persons living on it. Collection of stool samples was from patients who visit Collection of samples was from patients who visited El-Mekhwah, Ghamed Al-Zenad, Nawan and Al-Jowahand hospitals randomly. randomly. The total number of individuals examined in the studied area was 210 for Protozoan parasites and 300 for helminthes and this was done with the help of the hospital laboratory staff in the routine work. Stool specimens were examined microscopically after being prepared by the direct smear and formalinether concentration method (Fecal concentrator kit, then stained with lugol's iodine (1\%) to investigate the presence of Protozoa \& Helminthes Heidenhain's Iron Hematoxylin permanent stain was used to confirm the presence of Giardia lambia and Entamoeba histolytica. 


\section{Results}

Al-Mkhwah Province contains four healthy centrs . AlMkhwah; in the centre, Nawan (west). Ghamed AlZenad (South west) and Al-Jowah (North west). The presented work herewith was extended for two years 2013/2014 (1434 and 1435H.) to detect the prevalence and percentages of infection with intestinal parasites (Protozoa and Helminthes). Unfortunately no parasites were recorded in the examined samples in Al-Jowah dissert for the two years in the natives or the foreign expatriate workers.

The data are presented in Tables 1-6)of 210 fecal samples (117 males and 93 females) samples collected, $34(16.19 \%)$ were found to harbor protozoan infection. The overall prevalence among Saudi Arabia was 6,19\% Entamoeba histolytica, 6,19\% Entamoeba coli and $3.33 \%$ Giardia lambiaand. Also, females in the age group 21-25 show the highest infection rate with protozoa especially Entamobea histolytica (28.57\%). On the contrary, infection with intestinal protozoa was high among non-Saudi residents $(73.53 \%)$ compared to saudi citizens $26.47 \%$ a highly significant difference.

Also, of 300 patients examined $31(10.33 \%)$ were recorded to harbor intestinal helminthes. These were $4.33 \%$ Hymenolips nana, 2\% Teania saginata and 4\% Ascaris lumbricoides (Table 5). The distribution of the infection was higher in the non-Saudi workers $76.5 \%$ for Hymenolips nana, $50 \%$ for Taenia saginata and $83.33 \%$ in case of Ascaris lumbicoides, in relation to the number of infected as percentages (Table 6). Moreover, small ages were usually more sensitive to infection than older one (Table 4) at the same time the infection was higher in females than males. Furthermore, Ascaris lumbrioideshad the highest rate of infection $18.37 \%$ at age 16-20, then Hemenolips nana $15.80 \%$ age 6-10, while the lowest was $6.02 \%$ for Taenia saginate age more than 25 year (Table 5). Nevertheless, the results showed that protozoan parasites were more prevalent than helminth parasites.

\section{Discussion}

The most important natural factors involved in the distribution of parasites is the climate because it helps to speed the evolution of parasites and speed of reproduction, whether in the soil or water or inside the bodies of organisms in case of low temperatures or low humidity where the parasite does not find the opportunity to multiply (Akano, et al., 1992, Taha et al., 2013). The human factors include every thing related to life style and level of human activities, cleanliness of the environment and water resources that drink and food eaten. Intestinal parsites could be transmitted through mouth by eating contaminated or poorly cooked food or by drinking or washing with contaminated waters or sometimes by bite of insect vectors or failing to maintain adequate hygiene toilets(Akano, et al., 1992, Taha et al., 2013).

In general the high percentages of the intestinal protozoa found in this study may be due to the good community hygiene efforts applied by the Saudi Government, and also to the self hygiene of the population in the study

Table (1): The distribution of samples and the prevalence of intestinal protozoa among the examined individuals in relation to age and sex:

\begin{tabular}{|c|c|c|c|c|c|c|c|c|c|c|c|c|}
\hline \multirow{3}{*}{\begin{tabular}{|c|}
$\begin{array}{c}\text { Sex } \\
\text { Infection }\end{array}$ \\
Age group
\end{tabular}} & \multicolumn{4}{|c|}{ Male } & \multicolumn{4}{|c|}{ Female } & \multicolumn{4}{|c|}{ Total } \\
\hline & \multirow{2}{*}{$\begin{array}{l}\text { No. } \\
\text { ex. }\end{array}$} & \multirow{2}{*}{$\%$} & \multicolumn{2}{|c|}{ + ve cases } & \multirow{2}{*}{$\begin{array}{l}\text { No. } \\
\text { ex. }\end{array}$} & \multirow{2}{*}{$\%$} & \multicolumn{2}{|c|}{ + ve cases } & \multirow{2}{*}{$\begin{array}{l}\text { No. } \\
\text { ex. }\end{array}$} & \multirow{2}{*}{$\%$} & \multicolumn{2}{|c|}{ + ve cases } \\
\hline & & & No. & $\%$ & & & No. & $\%$ & & & No. & $\%$ \\
\hline$<5$ & 9 & 7.69 & 0 & 0 & 7 & 7.53 & 0 & 0 & 16 & 7.62 & 0 & 0 \\
\hline 6-10 & 8 & 6.84 & 0 & 0 & 5 & 5.38 & 0 & 0 & 13 & 6.19 & 0 & 0 \\
\hline 11-15 & 6 & 5.13 & 2 & 33.33 & 8 & 8.60 & 1 & 12.50 & 14 & 6.66 & 3 & 21.42 \\
\hline $16-20$ & 16 & 13.68 & 3 & 18.75 & 7 & 7.53 & 1 & 14.29 & 23 & 10.95 & 4 & 17.39 \\
\hline $21-25$ & 18 & 15.38 & 4 & 22.22 & 14 & 15.05 & 4 & 28.57 & 32 & 15.25 & 8 & 25 \\
\hline$>25$ & 60 & 51.28 & 9 & 15 & 52 & 55.91 & 10 & 19.22 & 112 & 53.33 & 19 & 16.95 \\
\hline Total & 117 & 100 & 18 & 15.38 & 93 & 100 & 16 & 17.20 & 210 & 100 & 34 & 16.19 \\
\hline
\end{tabular}


Table (2): Showing the species of intestinal protozoa among the examined individuals in relation to age group

\begin{tabular}{|c|c|c|c|c|c|c|c|}
\hline \multirow{2}{*}{$\begin{array}{c}\text { Parasite } \\
\text { Age group }\end{array}$} & \multirow{2}{*}{$\begin{array}{l}\text { No. } \\
\text { ex. }\end{array}$} & \multicolumn{2}{|c|}{ Entamoeba histolytica } & \multicolumn{2}{|c|}{ Entamoeba coli } & \multicolumn{2}{|c|}{ Giardia lambia } \\
\hline & & No. & $\%$ & No. & $\%$ & No. & $\%$ \\
\hline$<5$ & 16 & 0 & 0 & 0 & 0 & 0 & 0 \\
\hline $6-10$ & 13 & 0 & 0 & 0 & 0 & 0 & 0 \\
\hline $11-15$ & 14 & 1 & 7.14 & 1 & 7.14 & 1 & 7.14 \\
\hline $16-20$ & 23 & 3 & 13.4 & 1 & 4.35 & 0 & 0 \\
\hline $21-25$ & 32 & 4 & 12.50 & 2 & 6.25 & 2 & 6.25 \\
\hline$>25$ & 112 & 5 & 4.46 & 10 & 8.92 & 4 & 4.46 \\
\hline Total & 210 & 13 & 6.19 & 14 & 6.66 & 7 & 3.33 \\
\hline
\end{tabular}

Table (3): Showing the distribution of intestinal helminthes in relation to nationality

\begin{tabular}{|c|c|c|c|c|c|c|}
\hline Nationality & \multirow{2}{*}{$\begin{array}{c}\text { No. } \\
\text { Infection }\end{array}$} & \multirow{2}{*}{$\%$} & \multicolumn{2}{|c|}{ Saudi } & \multicolumn{2}{|c|}{ Non-saudi } \\
\hline Parasite & & & No. & $\%$ & No. & $\%$ \\
\hline Entamoeba histolytica & 13 & 38.24 & 3 & 23.07 & 10 & 76.93 \\
\hline Entamoeba coli & 13 & 38.24 & 4 & 30.76 & 9 & 69.24 \\
\hline Giardia lambia & 8 & 23.52 & 2 & 25 & 6 & 75 \\
\hline Total & 34 & 100 & 9 & 26.47 & 25 & 73.53 \\
\hline
\end{tabular}

Table (4): The distribution of samples and the prevalence of intestinal helminthes among the examined individuals in relation to age and sex

\begin{tabular}{|c|c|c|c|c|c|c|c|c|c|c|c|c|}
\hline \multirow{3}{*}{$\begin{array}{c}\begin{array}{c}\text { Sex } \\
\text { Infection }\end{array} \\
\text { Age group }\end{array}$} & \multicolumn{4}{|c|}{ Male } & \multicolumn{4}{|c|}{ female } & \multicolumn{4}{|c|}{ total } \\
\hline & \multirow{2}{*}{$\begin{array}{l}\text { No. } \\
\text { ex. }\end{array}$} & \multirow{2}{*}{$\%$} & \multicolumn{2}{|c|}{ + ve cases } & \multirow{2}{*}{$\begin{array}{l}\text { No. } \\
\text { ex. }\end{array}$} & \multirow{2}{*}{$\%$} & \multicolumn{2}{|c|}{ + ve cases } & \multirow{2}{*}{$\begin{array}{l}\text { No. } \\
\text { ex. }\end{array}$} & \multirow{2}{*}{$\%$} & \multicolumn{2}{|c|}{ + ve cases } \\
\hline & & & No. & $\%$ & & & No. & $\%$ & & & No. & $\%$ \\
\hline$<5$ & 0 & 0 & 0 & 0 & 0 & 0 & 0 & 0 & 0 & 0 & 0 & 0 \\
\hline 6-10 & 15 & 11.36 & 2 & 13.33 & 28 & 13.69 & 4 & 17.39 & 38 & 12.66 & 6 & 15.79 \\
\hline $11-15$ & 21 & 15.91 & 7 & 33.33 & 28 & 16.66 & 2 & 7.14 & 49 & 16.34 & 9 & 18.37 \\
\hline $16-20$ & 31 & 23.49 & 1 & 3.23 & 44 & 26.20 & 7 & 15.91 & 75 & 25 & 8 & 10.67 \\
\hline $21-25$ & 22 & 16.66 & 1 & 4.55 & 33 & 19.64 & 2 & 6.06 & 55 & 18.33 & 3 & 5.45 \\
\hline$>25$ & 43 & 32.58 & 3 & 6.68 & 40 & 23.80 & 2 & 5 & 83 & 27.67 & 5 & 6.02 \\
\hline Total & 132 & 100 & 14 & 10.60 & 168 & 100 & 17 & 10.11 & 300 & 100 & 31 & 10.33 \\
\hline
\end{tabular}

Table (5): The species of intestinal helminthes among the examined individuals in relation to group

\begin{tabular}{|c|c|c|c|c|c|c|c|}
\hline \multirow{2}{*}{$\begin{array}{c}\text { Parasite } \\
\text { Age group }\end{array}$} & \multirow{2}{*}{$\begin{array}{l}\text { No. } \\
\text { exam }\end{array}$} & \multicolumn{2}{|c|}{ Hymenolips nana } & \multicolumn{2}{|c|}{ Taenia saginata } & \multicolumn{2}{|c|}{ Ascaris lumbricoides } \\
\hline & & No. & $\%$ & No. & $\%$ & No. & $\%$ \\
\hline$<5$ & 0 & 0 & 0 & 0 & 0 & 0 & 0 \\
\hline 6-10 & 38 & 6 & 15.80 & 0 & 0 & 0 & 0 \\
\hline 11-15 & 49 & 0 & 0 & 0 & 0 & 0 & 0 \\
\hline $16-20$ & 75 & 5 & 6.66 & 0 & 0 & 0 & 18.37 \\
\hline $21-25$ & 55 & 2 & 3.64 & 1 & 1.82 & 3 & 4 \\
\hline$>25$ & 83 & 0 & 0 & 5 & 6.02 & 0 & 0 \\
\hline Total & 300 & 13 & 4.33 & 6 & 2 & 12 & 4 \\
\hline
\end{tabular}


Table (6): The distribution of intestinal helminthes in relation to nationality

\begin{tabular}{|c|c|c|c|c|c|c|}
\hline \multirow{2}{*}{ Nationality } & \multirow{2}{*}{ No. Infection } & \multirow{2}{*}{$\%$} & \multicolumn{2}{|c|}{ Saudi } & \multicolumn{2}{c|}{ Non-Saudi } \\
\cline { 3 - 7 } & & & No. & $\%$ & No. & 76.50 \\
\hline Parasite & 13 & 41.94 & 3 & 23.08 & 3 & 50 \\
\hline Tamenolips nana & 6 & 19.35 & 3 & 50 & 10 & 83.33 \\
\hline Ascaris lumbricoides & 12 & 38.71 & 2 & 25.81 & 23 & 74.19 \\
\hline Total & 31 & 100 & 8 & & & \\
\hline
\end{tabular}

area. The intestinal Protozoa found in the studied area may be due to eating of vegetables contaminated with cysts of these intestinal protozoa without good washing (Bangs, et al., 1996). The high prevalence of intestinal parasites found among non-Saudi residents may be due to the type of the work they do, some of them are farmers that may eat fresh vegetables directly from the field without care, and also take meals at the restaurants (Chosy, et al., 1990; Gbakima, 1994 and Karra and Rahim, 1995). The present results showed lower results than previously published results on Saudi natives or foreign expatriate workers (Abahussain, 2005; AlHarthi and Jamjoom, 2007 Zaglool et al., 2011 and Taha et al., 2013) and this may be mainly due to environmental factors because this province usually appear as a cut area surrounded by mountains from all sides with low population density.

\section{References}

Abahussain, N. A. (2005). Prevalence of intestinal parasites among expatriate workers in $\mathrm{Al}$ Khobar, Saudi Arabia. Middle East Journal of Family Medicine 33(3): 17-21.

Aknao, N, Ohyama. Ohkawa, T, Kondo, K, hirokawa, Y., Ito, S., Tokeguchi-A, Mastsuzaki, M. (1992). A survey of intestinal parasites of foreign labors (Indonesians and Filipinonos). Kabsebshogakwzasshi, 66(9): 1256-61.

Albonico, M., Carneri, I. De., Matteo, LD., Ghightti, R., Toscano, P., Uledi M. K., Savioli, L., De Carneri, I., Di, Matteo, L. (1993). Intestinal parasitic infections of urban and rural children on pemba Island implications of control. Ann. Trop. Med. Parasitol. 87(6): 579-583.

Al-Harthi, S. A. \& Jamjoom, M. B. (2007). Preliminary study of the prevalence of intestinal parasites among diarrheic inhabitants in Makkah AlMukarramah. J. Egyp. Soc. Parasitol., (37(2): 671-680.

Bangs, M. J., Andersen, P.E.M. and Anthony R.L. (1996). Intestinal parasites of human in high land community of Irian Jaya, Indonesia. Annals of Tropical medicine and parasitology. 90(1): 49-53.

Celiksoz, A., Gufer, G., Oztop, A. Y. and Degerli, S. (2005). Prevalence of intestinal parasites in three socioeconomically different regions of Sivs, Turkey. Universal Toronto Library 23: 134-191.

Chandler, A.C. and Read, C.P. (1964). Introduction to Parasitology.. John Wiley and Sons. New York.

Chosy, Kim-JH, Park -SH. (1990). Status of intestinal parasites infection in inhabitants of palmar, Guayas, province-Ecuador. Kisaengchughak-chapchi. 28(2): 109-13.

Eve, E., Ferraz, E. and Thatcher, V. E. (1998). Parasitic infection in villagers fro three district of Parazithian Amazon. Annals of Tropical Medicine and parasitology. 92(1): 79-87.

Gbakima-AA. (1994). Intestinal parasitic infection and swamp development in Sierra Leon. African Journal of Health Sciences 1(4): 175-178. 13 ref.

Karrar, Z. A. and A. Rahim, F. (1995). Prevalence and Risk Factors of parasitic infection Among under five Sudaness children-A common based study. East African Medical Journal. 72(2): 103-108.

Mohammad, K. A. and Koshak, E.A. (2011). A prospective study on parasites among expatriate workers in Al-Baha from 2009-2011. Saudi Arabia. Journal Egyptian Society of Parasitology, 41(2): 423-432.

Savioli, L., Albonico, M., Engels, D. and Montresor, A. (2004). Progress in he prevention and control of schistosomiasis and soil-transmitted helminthiasis. Parasitol. Int., 53(2): 103-113.

Taha, H.A., Soliman, M. I. and Banjor, S. A. N. (2013). Intestinal parasitic infection among expatriate workers in Al-Maina El-Munawarah, Kingdom of Saudi Arabia. Tropical Biomedicine. 30(1): 1-11.

Wakid, M. H., Azhar, E. I. and Zafar, T. A. (2009). Intestinal parasitic infection among food handlers in the Holy City of Makkah during Hajj season 1428 Hegira (2007G). Journal of King Abul Aziz University Medical Science, 16(1): 39-52.

Zaghlool, D.A., Khodari, Y. A., Othman, R. A. M. and Farooq, M. U. (2011). Prevalence of intestinal parasites and bacteria among food handlers in a tertiary care hospital. Nigerian Medical Journal, 52(4): 266-270. 